\title{
Thyroid Cancer Brain Metastases and Thyroglobulin
}

\author{
Bernardo Cacho-Diaz ${ }^{\mathrm{a}}$, d, Daniel Cuevas-Ramos ${ }^{\mathrm{b}}$, Hector Spinola-Marono $^{\mathrm{a}}$, Gervith Reyes-Soto ${ }^{\mathrm{a}}$, \\ Eduardo Olvera-Manzanilla ${ }^{a}$, Alejandro Monroy-Sosa ${ }^{a}$, Nydia Arelly Lorenzana-Mendoza ${ }^{a}$, \\ Martin Granados-Garcia ${ }^{\mathrm{a}}$, Angel Herrera-Gomez ${ }^{\mathrm{c}}$
}

\begin{abstract}
Background: Thyroid cancer (TC) is the most common endocrine cancer. The majority of patients reach long survival rates, but $10-15 \%$ of patients show recurrent disease, and 5\% have distant metastases. Brain metastases (BMs) from TC are rare and carry high morbidity and mortality.
\end{abstract}

Methods: From January 2010 to December 2015, nearly 400 patients with TC were treated at a tertiary referral center. This study reports the findings of all seven patients with BM, which were compared to historical controls.

Results: Male patients and older age are associated with a higher frequency of distant metastases from TC. Among patients with BM, surgical excision when indicated, followed by whole brain radiotherapy, was the treatment associated with longest survival rates.

Conclusion: Thyroglobulin was the most useful serum marker to diagnose recurrence or distant disease. High levels of thyroglobulin (mean: 15,029; IQR: 300 - 13,687) were mainly associated with BMs.

Keywords: Thyroid; Cancer; Thyroglobulin; Metastases; Brain

\section{Introduction}

Thyroid cancer (TC) accounts for more than $90 \%$ of all endocrine malignancies but represents only about $1 \%$ of all human cancers [1]. Differentiated thyroid cancer (DTC) that arises from

\footnotetext{
Manuscript accepted for publication May 18, 2016

${ }^{a}$ Neuroscience Unit, Instituto Nacional de Cancerologia, Mexico City, Mexico bepartment of Endocrinology, Instituto Nacional de Ciencias Medicas y Nutricion Salvador Zubiran, Mexico City, Mexico

'Instituto Nacional de Cancerologia, Mexico City, Mexico

${ }^{\mathrm{d} C o r r e s p o n d i n g ~ A u t h o r: ~ B e r n a r d o ~ C a c h o-D i a z, ~ N e u r o s c i e n c e ~ U n i t ~(U n i d a d ~ d e ~}$ Neurociencias), Instituto Nacional de Cancerologia, Av. San Fernando 22 Col, Seccion XVI, Mexico City 14080, Mexico.

Email: bernardocacho@doctor.com
}

doi: http://dx.doi.org/10.14740/jem351w the thyroid follicular cells accounts for more than $90 \%$ of TC cases diagnosed; within this group, papillary TC $(90 \%)$ and follicular $(10 \%)$ account for more than $90 \%$ of new cases, whereas around $10 \%$ of patients develop medullary TC [2]. DTC is initially treated with surgery (e.g., total thyroidectomy and central lymph node dissection), followed by radioiodine treatment in patients with a substantial risk of persistent or recurrent disease [3]. Follow-up with neck ultrasonography and measurement of serum thyroglobulin $(\mathrm{Tg})$ concentration after stimulation with recombinant human thyroid stimulating hormone (TSH) or after thyroid hormone withdrawal contributes to the detection of persistent or recurrent diseases. More than $85 \%$ of patients with DTC express a limited disease and become disease-free after initial treatment [4]. Nearly $10-15 \%$ of patients with TC have recurrent disease, and about $5 \%$ show distant metastases at presentation. In $75 \%$ of the patients with recurrent disease, tumor cells are located more often inside the neck lymph nodes [5]. No randomized controlled trials assessing primary treatment or treatment of recurrent disease have been reported [3]. Patients with recurrent disease outside the neck structures usually show lung micrometastases or bone infiltrations [5]. Brain metastases (BMs) from TC, however, are quite rare, involving only $0.5-2.3 \%$ of all DTC cases [6-12]. Prognosis is usually poor due to its high morbidity and mortality rates.

\section{Materials and Methods}

From January 2010 through December 2015, TC patients seen at a tertiary referral center that required neurological consultation were included. Demographic and radiologic characteristics were described as well as their clinical prognosis. Serum $\mathrm{Tg}$, TSH and anti-Tg antibodies were measured as previously reported [13]. Serum Tg from patients with TC and BM (group 1) was compared to patients with TC during follow-up at the thyroid cancer clinic. Group 2 included patients with TC and systemic (outside brain)/local disease, and group 3 included TC cases with no systemic/local disease. Our local IRB and ethics committee approved all interventions.

\section{Results}

During the study period, 384 new patients were diagnosed 
Table 1. Characteristics of Seven Patients With Thyroid Cancer and Brain Metastases

\begin{tabular}{|c|c|c|c|c|c|c|c|c|c|}
\hline Case & Gender & $\begin{array}{l}\text { Age } \\
\text { (years) }\end{array}$ & Histology & $\begin{array}{l}\text { Time for BM from } \\
\text { diagnosis (months) }\end{array}$ & $\begin{array}{l}\text { Tg } \\
(\mathrm{ng} / \mathrm{mL})\end{array}$ & $\begin{array}{l}\text { Other sites } \\
\text { affected }\end{array}$ & $\begin{array}{l}\text { Number and } \\
\text { size }(\mathrm{mm}) \text { of } \mathrm{BM}\end{array}$ & Treatment & $\begin{array}{l}\text { Survival } \\
\text { (months) }\end{array}$ \\
\hline 1 & $\mathrm{~F}$ & 65 & PD follicular & 5 & 8,555 & Local, lung & S 41 & WBRT & 7 \\
\hline 3 & M & 50 & WD papillary & 20 & 13,687 & Local, bone, lung & M 57 & WBRT & 6 \\
\hline 4 & M & 54 & WD papillary & 29 & 24,551 & Local, bone, lung & M 38 & WBRT & 1 \\
\hline 6 & $\mathrm{~F}$ & 56 & WD papillary & 31 & 8,555 & Local, lung & S 41 & Qx + WBRT & 34 \\
\hline 7 & M & 72 & PD papillary & 9 & 849 & Local, bone, lung & M 10 & WBRT & 13 \\
\hline
\end{tabular}

WD: well differentiated; PD: poorly differentiated; S: single; M: multiple; WBRT: whole brain radiotherapy; Qx: surgical resection; Tg: thyroglobulin.

with TC [14] and $61(16 \%)$ were referred for a neurological evaluation. Seven patients were then detected with BM. Baseline characteristics are described in Table 1. Mean age at diagnosis was 59 years (range: 50 - 72 years) with a mean interval between the diagnosis of TC and BM of 16 months (range: 1 - 31 months). All patients had other sites of metastases at the time BMs were detected. Three patients showed single brain metastasis, two of whom were declared candidates for surgical resection followed by whole brain radiotherapy (WBRT). Mean maximum diameter of metastases was $40 \mathrm{~mm}$ (range: 10 - $57 \mathrm{~mm}$ ). Mean survival time was 17 months (range: 1 - 58 months). Most patients died due to complications related either to BM or systemic disease.

Serum Tg of patients with BM (group 1, $\mathrm{n}=7$ ) had a mean value of 8,087 ng/mL (range: 116 - 24,551; IQR: 300 13,687). Mean Tg for patients with local or systemic disease (group 2, n = 20) was 210 (range: 8.4 - 1,832; IQR: 30 - 125) and mean $\mathrm{Tg}$ for those patients with no evidence of neoplastic activity (group 3, $\mathrm{n}=99$ ) was 2.4 (range: $0.2-47$; IQR: 0.2 - 1) with a statistical significance $(\mathrm{P}<0.0001)$ as shown in Figure 1.

\section{Discussion}

We report seven patients with $\mathrm{TC}$ and $\mathrm{BM}$ at a single tertiary referral unit. The female to male ratio for the cohort with BM was of $1: 2.5$, in contrast to the overall gender ratio of 2-4:1 for patients with TC $[6,15]$. Some authors support the theory of a higher relative risk of distant metastases among male patients. After reviewing 131 cases reported [6-8, 11, 16-29] including our seven patients (82 female and 56 male patients with TC and $\mathrm{BM})$, there is a female to male ratio of $1.5: 1$, further supporting the hypothesis of a higher proportion of BM among the male population. It has been suggested that male patients, older in age, with larger primary tumors, and frequent evidence of extrathyroidal invasion tend to have distant metastases, including BM $[15,16,18,30]$ and have shown to be independent predictors of prognosis [31-34]. There are different staging and scoring systems to distinguish between patients at low or high

\section{Thyroglobulin levels according to groups}

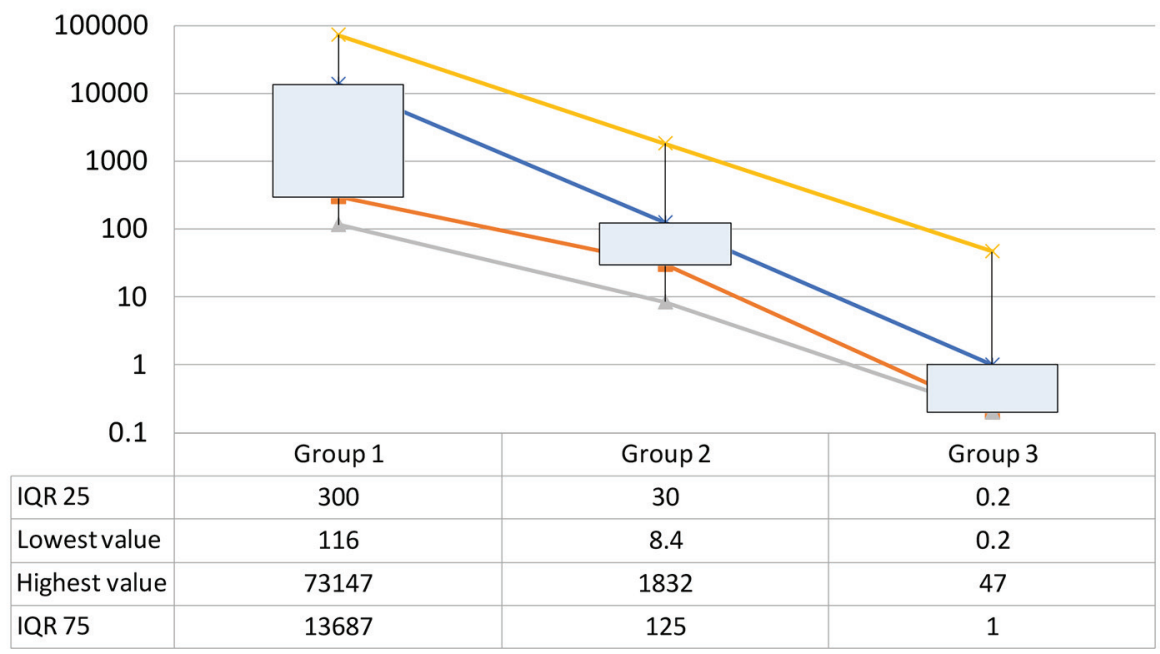

Figure 1. Thyroglobulin levels in patients with brain metastases from thyroid cancer (TC) (group 1), TC with systemic/local disease (group 2), and TC with no evidence of disease. 
risk of cancer-related death [5, 34-36], but they are beyond the scope of this study. The average interval between diagnosis of TC and BM was 15.7 months (range: 1 - 31 months), the same as others $[17,18,25]$.

The median survival for patients with BM from TC treated at our center was 17 months, higher than some [6] but similar to others $[16,18,25]$. Histologically, well-differentiated (WD) papillary cancer was found in five and two with anaplastic component (one follicular and one papillary). Patients with anaplastic carcinoma had a different survival rate (mean: 10 vs. 20 months for WDTC), but did not reach statistical significance found by others [17]. BMs had a high negative effect on survival (mean: 6.7 vs. 25 months for those without BMs, P: NS) also found by others [17].

Solitary metastases from TC have been established. In our series, three patients had single BM (43\%), but only two were considered candidates for surgical resection followed by WBRT. The remaining patient showed a very poor performance status. Solitary metastases were thought to be rare [19], but as more cases have been reported, cases have increased up to $46 \%$ of patients with BM from TC [16].

Surgery, followed by WBRT as a treatment modality of BM, has shown to improve survival rates [37]. In our series, patients treated surgically had a longer survival average (mean: 46 vs. 5.6 months for those who were not candidates for metastasectomy, $\mathrm{P}=0.003$ ) similar to others $[6,16]$. However, selection bias is likely a factor in the improved survival because those patients who have solitary or few lesions and are considered appropriate candidates for surgery are likely to have a longer survival. Gamma knife radiosurgery may play a key role in the management of BM from TC for its effectiveness and minimal invasive nature [16, 23, 27].

Treatment with radioactive iodine should be considered because it has been reported to improve response of distant metastases including BM $[9,11,24]$. However, there is a risk of cerebral edema.

Persistence, recurrence, or locoregional metastases of DTC, most commonly involve lymph nodes in neck and are usually detected by measurement of serum $\mathrm{Tg}$ concentrations, combined with physical examination, high resolution ultrasonography, or other imaging strategies and, if required, fine-needle aspiration biopsy (FNAB) with Tg measurement where available [38]. Serial Tg levels are recommended for follow-up [39], specially after the use of recombinant human TSH or cessation of thyroid replacement therapy [40-42]. Tg is a specific and extremely useful tumor marker for follow-up of patients with TC $[4,15,43]$.

High Tg levels have been associated with residual or distant disease from TC $[5,9,44]$. We found higher levels of Tg in patients with BM or systemic disease, but significantly higher for those with BM (mean 15,029 ng/mL) than for the ones with systemic disease (mean: $210 \mathrm{ng} / \mathrm{mL}$ ) and for those with no local or systemic disease (mean: $2.4 \mathrm{ng} / \mathrm{mL} ; \mathrm{P}<0.0001$ ). This result is consistent with previous reports $[22,25,31]$. There are some reports of patients with BM from TC with normal $\operatorname{Tg}[11,27]$, suggesting very dedifferentiated tumors. Serum $\mathrm{Tg}$ level also correlates independently with survival rates [45]. The findings achieved in this study need to be further studied because a referral bias may exist.

\section{Conclusion}

$\mathrm{BM}$ from $\mathrm{TC}$ is a rare complication with a poor prognosis. Male patients and older age are associated with a higher frequency of distant metastases from TC. Among patients with $\mathrm{BM}$, surgical excision when indicated, followed by WBRT is the treatment associated with the longest survival rates. Tg is a useful tumor marker for follow-up in patients with TC; high levels are associated with recurrence or distant disease and very high levels with BMs.

\section{References}

1. Tuttle RM, Leboeuf R, Martorella AJ. Papillary thyroid cancer: monitoring and therapy. Endocrinol Metab Clin North Am. 2007;36(3):753-778, vii.

2. Hundahl SA, Cady B, Cunningham MP, Mazzaferri E, McKee RF, Rosai J, Shah JP, et al. Initial results from a prospective cohort study of 5583 cases of thyroid carcinoma treated in the united states during 1996. U.S. and German Thyroid Cancer Study Group. An American College of Surgeons Commission on Cancer Patient Care Evaluation study. Cancer. 2000;89(1):202-217.

3. Baudin E, Schlumberger M. New therapeutic approaches for metastatic thyroid carcinoma. Lancet Oncol. 2007;8(2):148-156.

4. Pacini F, Schlumberger M, Dralle H, Elisei R, Smit JW, Wiersinga W. European consensus for the management of patients with differentiated thyroid carcinoma of the follicular epithelium. Eur J Endocrinol. 2006;154(6):787-803.

5. Tubiana M, Schlumberger M, Rougier P, Laplanche A, Benhamou E, Gardet P, Caillou B, et al. Long-term results and prognostic factors in patients with differentiated thyroid carcinoma. Cancer. 1985;55(4):794-804.

6. Chiu AC, Delpassand ES, Sherman SI. Prognosis and treatment of brain metastases in thyroid carcinoma. J Clin Endocrinol Metab. 1997;82(11):3637-3642.

7. Ota T, Bando Y, Hirai M, Tanaka N, Takabatake Y, Kasahara Y, Fujisawa M. Papillary carcinoma of the thyroid with distant metastases to the cerebrum: a case report. Jpn J Clin Oncol. 2001;31(3):112-115.

8. Carcangiu ML, Zampi G, Pupi A, Castagnoli A, Rosai J. Papillary carcinoma of the thyroid. A clinicopathologic study of 241 cases treated at the University of Florence, Italy. Cancer. 1985;55(4):805-828.

9. Durante C, Haddy N, Baudin E, Leboulleux S, Hartl D, Travagli JP, Caillou B, et al. Long-term outcome of 444 patients with distant metastases from papillary and follicular thyroid carcinoma: benefits and limits of radioiodine therapy. J Clin Endocrinol Metab. 2006;91(8):2892-2899.

10. Hoie J, Stenwig AE, Kullmann G, Lindegaard M. Distant metastases in papillary thyroid cancer. A review of 91 patients. Cancer. 1988;61(1):1-6.

11. Hjiyiannakis P, Jefferies S, Harmer CL. Brain metastases in patients with differentiated thyroid carcinoma. Clin Oncol (R Coll Radiol). 1996;8(5):327-330.

12. Benbassat CA, Mechlis-Frish S, Hirsch D. Clinicopatho- 
logical characteristics and long-term outcome in patients with distant metastases from differentiated thyroid cancer. World J Surg. 2006;30(6):1088-1095.

13. Robbins RJ, Chon JT, Fleisher M, Larson SM, Tuttle RM. Is the serum thyroglobulin response to recombinant human thyrotropin sufficient, by itself, to monitor for residual thyroid carcinoma? J Clin Endocrinol Metab. 2002;87(7):3242-3247.

14. Granados Garcia M, Leon Takahashi AM, Guerrero Huerta FJ, Taissoun Aslan ZA. [Differentiated thyroid cancer: an ancient disease with new knowledge]. Gac Med Mex. 2014;150(1):65-77.

15. Schlumberger MJ. Papillary and follicular thyroid carcinoma. N Engl J Med. 1998;338(5):297-306.

16. McWilliams RR, Giannini C, Hay ID, Atkinson JL, Stafford SL, Buckner JC. Management of brain metastases from thyroid carcinoma: a study of 16 pathologically confirmed cases over 25 years. Cancer. 2003;98(2):356-362.

17. Salvati M, Frati A, Rocchi G, Masciangelo R, Antonaci A, Gagliardi FM, Delfini R. Single brain metastasis from thyroid cancer: report of twelve cases and review of the literature. J Neurooncol. 2001;51(1):33-40.

18. Biswal BM, Bal CS, Sandhu MS, Padhy AK, Rath GK. Management of intracranial metastases of differentiated carcinoma of thyroid. J Neurooncol. 1994;22(1):77-81.

19. Goolden AW, McLaughlin JE, Valentine AR, Pease C. Solitary cerebral metastasis from a papillary carcinoma of the thyroid. Postgrad Med J. 1990;66(772):127-129.

20. Olson AC, Haugen BR, Walter J, Kwak JJ, Bagrosky BM, Koo PJ. SPECT/CT and I131 therapy of brain metastases from follicular variant papillary thyroid carcinoma (FVPTC). J Clin Endocrinol Metab. 2014;99(10):35113512.

21. Diyora B, Nayak N, Kamble H, Sharma A. Brain metastasis from papillary carcinoma of thyroid gland. J Neurosci Rural Pract. 2010;1(1):55-57.

22. Pazaitou-Panayiotou K, Kaprara A, Chrisoulidou A, Boudina M, Georgiou E, Patakiouta F, Drimonitis A, et al. Cerebellar metastasis as first metastasis from papillary thyroid carcinoma. Endocr J. 2005;52(6):653-657.

23. Kim IY, Kondziolka D, Niranjan A, Flickinger JC, Lunsford LD. Gamma knife radiosurgery for metastatic brain tumors from thyroid cancer. J Neurooncol. 2009;93(3):355-359.

24. Vrachimis A, Schmid KW, Jurgens H, Schober O, Weckesser M, Riemann B. Cerebral metastases from thyroid carcinoma: complete remission following radioiodine treatment. Dtsch Arztebl Int. 2013;110(50):861-866.

25. Misaki T, Iwata M, Kasagi K, Konishi J. Brain metastasis from differentiated thyroid cancer in patients treated with radioiodine for bone and lung lesions. Ann Nucl Med. 2000;14(2):111-114.

26. Ogawa Y, Sugawara T, Seki H, Sakuma T. Thyroid follicular carcinoma metastasized to the lung, skull, and brain 12 years after initial treatment for thyroid gland - case report. Neurol Med Chir (Tokyo). 2006;46(6):302-305.

27. Anoop TM, Mini PN, Divya KP, Nikhil S, Jabbar PK. Clinical images. Thyroid follicular carcinoma presenting as intraorbital, intracranial, and subcutaneous metastasis.
Am J Surg. 2010;199(6):e72-74.

28. Aguiar PH, Agner C, Tavares FR, Yamaguchi N. Unusual brain metastases from papillary thyroid carcinoma: case report. Neurosurgery. 2001;49(4):1008-1013.

29. Isoda H, Takahashi M, Arai T, Ramsey RG, Yokoyama T, Mochizuki T, Yamamoto I, et al. Multiple haemorrhagic brain metastases from papillary thyroid cancer. Neuroradiology. 1997;39(3):198-202.

30. Hay ID. Brain metastases from papillary thyroid carcinoma. Arch Intern Med. 1987;147(3):607, 611.

31. Palme CE, Waseem Z, Raza SN, Eski S, Walfish P, Freeman JL. Management and outcome of recurrent welldifferentiated thyroid carcinoma. Arch Otolaryngol Head Neck Surg. 2004;130(7):819-824.

32. Shoup M, Stojadinovic A, Nissan A, Ghossein RA, Freedman S, Brennan MF, Shah JP, et al. Prognostic indicators of outcomes in patients with distant metastases from differentiated thyroid carcinoma. J Am Coll Surg. 2003;197(2):191-197.

33. Haq M, Harmer C. Differentiated thyroid carcinoma with distant metastases at presentation: prognostic factors and outcome. Clin Endocrinol (Oxf). 2005;63(1):87-93.

34. Mihailovic J, Stefanovic L, Malesevic M. Differentiated thyroid carcinoma with distant metastases: probability of survival and its predicting factors. Cancer Biother Radiopharm. 2007;22(2):250-255.

35. Cady B, Rossi R. An expanded view of risk-group definition in differentiated thyroid carcinoma. Surgery. 1988;104(6):947-953.

36. Hay ID, Grant CS, Taylor WF, McConahey WM. Ipsilateral lobectomy versus bilateral lobar resection in papillary thyroid carcinoma: a retrospective analysis of surgical outcome using a novel prognostic scoring system. Surgery. 1987;102(6):1088-1095.

37. Patchell RA, Tibbs PA, Walsh JW, Dempsey RJ, Maruyama Y, Kryscio RJ, Markesbery WR, et al. A randomized trial of surgery in the treatment of single metastases to the brain. N Engl J Med. 1990;322(8):494-500.

38. Snozek CL, Chambers EP, Reading CC, Sebo TJ, Sistrunk JW, Singh RJ, Grebe SK. Serum thyroglobulin, high-resolution ultrasound, and lymph node thyroglobulin in diagnosis of differentiated thyroid carcinoma nodal metastases. J Clin Endocrinol Metab. 2007;92(11):4278-4281.

39. Girelli ME, De Vido D. Serum thyroglobulin measurements in differentiated thyroid cancer. Biomed Pharmacother. 2000;54(6):330-333.

40. Baudin E, Do Cao C, Cailleux AF, Leboulleux S, Travagli JP, Schlumberger M. Positive predictive value of serum thyroglobulin levels, measured during the first year of follow-up after thyroid hormone withdrawal, in thyroid cancer patients. J Clin Endocrinol Metab. 2003;88(3):11071111.

41. Kloos RT, Mazzaferri EL. A single recombinant human thyrotropin-stimulated serum thyroglobulin measurement predicts differentiated thyroid carcinoma metastases three to five years later. J Clin Endocrinol Metab. 2005;90(9):5047-5057.

42. Mazzaferri EL, Robbins RJ, Spencer CA, Braverman LE, Pacini F, Wartofsky L, Haugen BR, et al. A consensus re- 
port of the role of serum thyroglobulin as a monitoring method for low-risk patients with papillary thyroid carcinoma. J Clin Endocrinol Metab. 2003;88(4):1433-1441.

43. Ronga G, Filesi M, Ventroni G, Vestri AR, Signore A. Value of the first serum thyroglobulin level after total thyroidectomy for the diagnosis of metastases from differentiated thyroid carcinoma. Eur J Nucl Med. 1999;26(11):1448-1452.
44. Herle AJ, Uller RP. Elevated serum thyroglobulin. A marker of metastases in differentiated thyroid carcinomas. J Clin Invest. 1975;56(2):272-277.

45. Robbins RJ, Wan Q, Grewal RK, Reibke R, Gonen M, Strauss HW, Tuttle RM, et al. Real-time prognosis for metastatic thyroid carcinoma based on 2-[18F]fluoro2-deoxy-D-glucose-positron emission tomography scanning. J Clin Endocrinol Metab. 2006;91(2):498-505. 